\title{
ON A FIXED POINT THEOREM OF PATHAK
}

\author{
BRIAN FISHER \\ Department of Mathematics \\ The University \\ Leicester LE1 7RH \\ England
}

(Received October 11, 1989)

\begin{abstract}
It is shown that the continuity of the mapping in Pathak's fixed point theorem for
\end{abstract} normed spaces is not necessary.

KEY WORDS AND PHRASES. Normed space, Fixed Point. 1980 AMS SUBJECT CLASSIFICATION CODE. 47H10.

1. INTRODUCTION AND MAIN RESULTS.

In [1] Pathak gives the following definitions:

DEFINITION 1. Let $\mathrm{X}$ be a normed vector space; then $\mathrm{T}$, a self mapping of $\mathrm{X}$ is called a 'generalized contractive mapping' if

$$
\begin{aligned}
\|T x-T y\| \leq q \max \left\{\|x-y\|, \frac{\|x-T x\|[1-\|x-T y\|]}{1+\|x-T x\|},\right. \\
\frac{\|x-T y\|[1-\|x-T x\|]}{1+\|x-T y\|}, \frac{\|y-T x\|[1-\|y-T y\|}{1+\|T x-y\|}, \\
\frac{\|y-T y\|[1-\|T x-y\|]}{1+\|y-T y\|},
\end{aligned}
$$

for all $x, y$ in $X$, where $0<q<1$.

DEFINITION 2. Let $\mathrm{T}$ be a self mapping of a Banach space $\mathrm{X}$. The Mann iterative process associated with $\mathrm{T}$ is defined in the following manner:

Let $x_{0}$ be in $X$ and set $x_{n+1}=\left(1-c_{n}\right) x_{n}+c_{n} T x_{n}$, for $n \geq 0$, where $c_{n}$ satisfies (i) $c_{o}=1$, (ii) $0<c_{n}<1$ for $n>0$, (iii) $\lim _{n \rightarrow \infty} c_{n}=h>0$.

He then proves the following theorem:

THEOREM. Let $X$ be a closed, convex subset of a normed space $N$, let $T$ be a generalized contractive mapping of $\mathrm{X}$ with $\mathrm{T}$ continuous on $\mathrm{X}$, and let $\left\{x_{n}\right\}$, the sequence of Mann iterates associated with $\mathrm{T}$, be the same as defined above where $\left\{c_{n}\right\}$ satisfies (i), (ii) and (iii). If $\left\{x_{n}\right\}$ converges in $\mathrm{X}$, then it converges to a fixed point of $\mathrm{T}$. 
Pathak finally asks if the continuity of $\mathrm{T}$ is necessary in the theorem for $\mathrm{T}$ to have a fixed point.

The answer is in the affirmative. To see this, note that if $\mathrm{T}$ is a generalized contractive mapping then $\mathrm{T}$ also satisfies the inequality

$$
\|T x-T y\| \leq q \max \{\|x-y\|,\|x-T x\|,\|x-T y\|,\|y-T x\|,\|y-T y\|\}
$$

for all $x, y$ in $X$, where $0<q<1$.

Using inequality (1.2) now instead of inequality (1.1) to simplify the work, it follows in exactly the same way as in Pathak's proof of the theorem that if $\lim _{n} x_{\infty} x_{n}=z$, then

$\|z-T z\| \leq\left\|z-x_{n+1}\right\|+\left(1-c_{n}\right)\left\|x_{n}-T z\right\|$

$+c_{n} q \max \left\{\left\|x_{n}-z\right\|,\left\|x_{n}-T x_{n}\right\|,\left\|x_{n}-T z\right\|,\left\|T x_{n}-z\right\|,\|z-T z\|\right\}$

It now follows from the definition of $x_{n}$ in Definition 2 that

and so

$$
T x_{n}=\frac{x_{n+1}-\left(1-c_{n}\right) x_{n}}{c_{n}}
$$

$$
\lim _{n \rightarrow \infty} T x_{n}=z
$$

On letting $n$ tend to infinity in inequality (1.3) we now have

$$
\begin{aligned}
\|z-T z\| \leq & (1-h)\|z-T z\|+h q \max \{0,\|z-T z\|\} \\
& =(1-h+h q)\|z-T z\|,
\end{aligned}
$$

where $1-h+h q<1$. Thus $T z=z$.

\section{REFERENCES}

1. PATHAK, H.K., Some Fixed Point Theorems on Contractive Mappings, Bull. Cal. Math. Soc. 80, 183. 


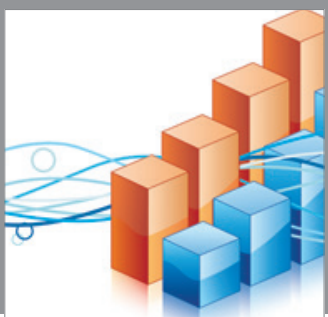

Advances in

Operations Research

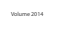

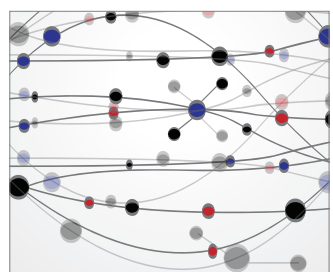

\section{The Scientific} World Journal
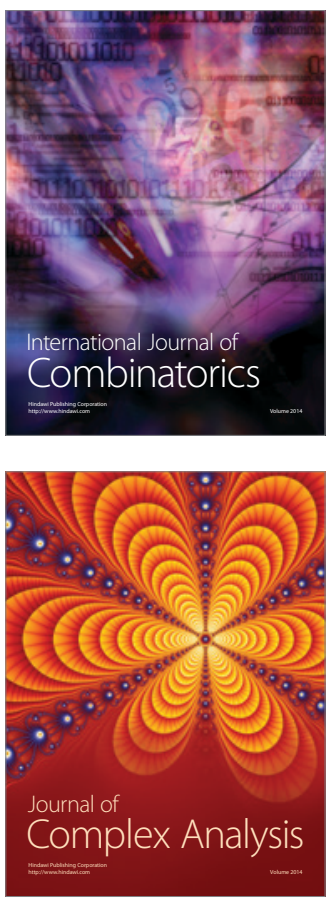

International Journal of

Mathematics and

Mathematical

Sciences
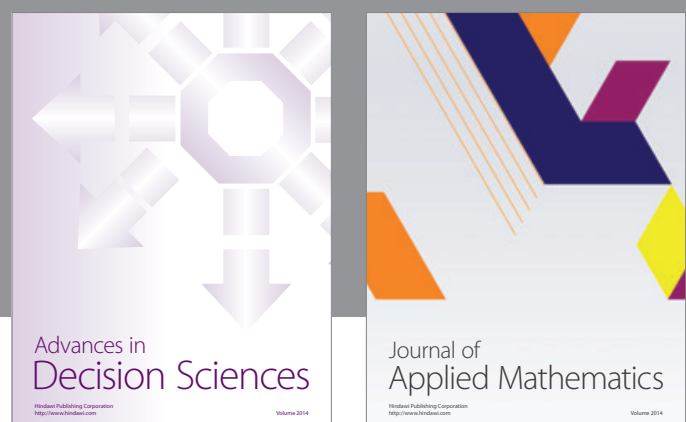

Journal of

Applied Mathematics
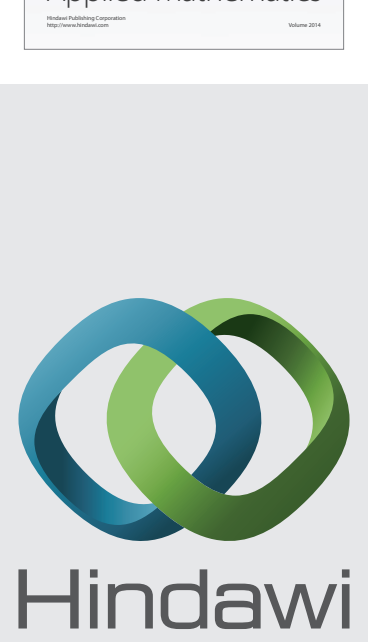

Submit your manuscripts at http://www.hindawi.com
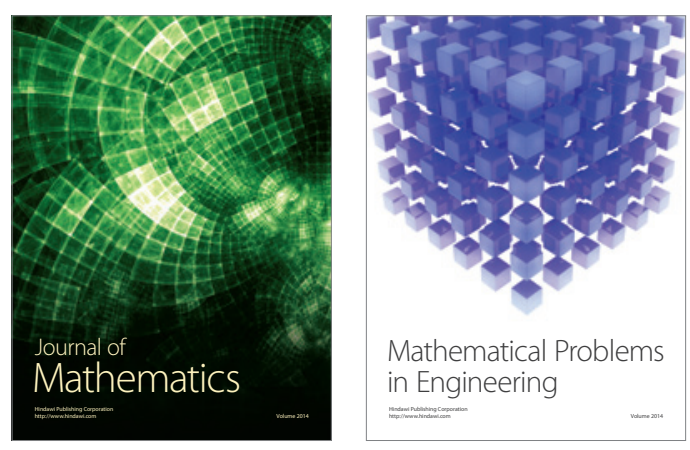

Mathematical Problems in Engineering
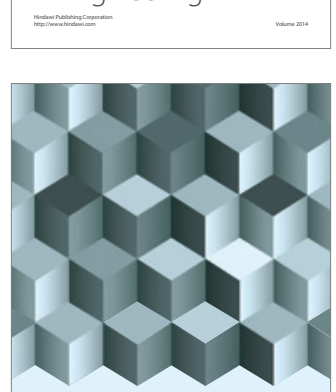

Journal of

Function Spaces
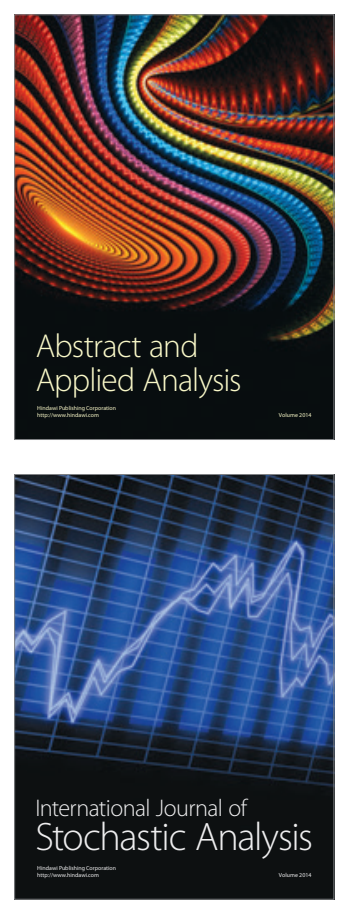

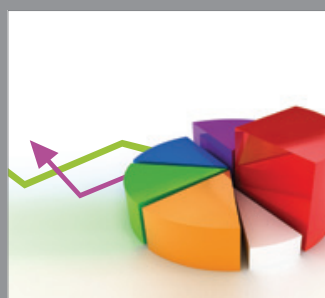

ournal of

Probability and Statistics

Promensencen
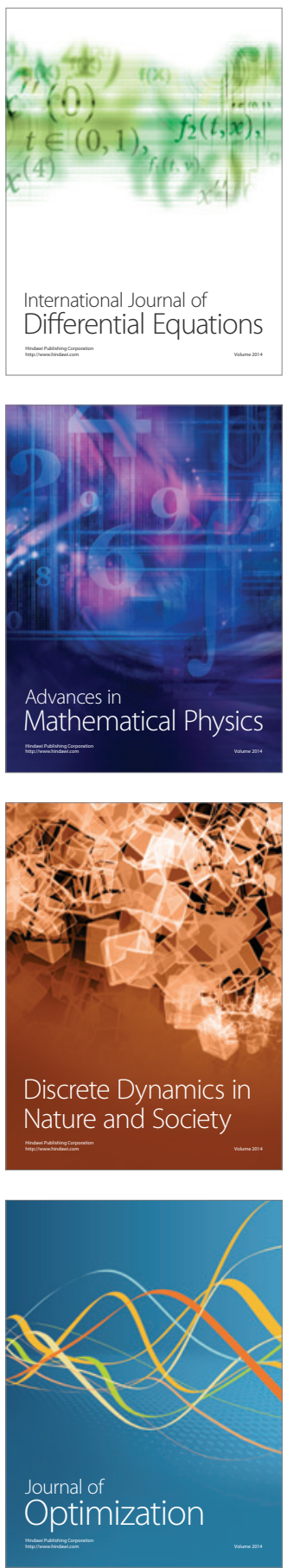